\title{
Elevated Levels of the Chemokine GRO-1 Correlate with Elevated Oligodendrocyte Progenitor Proliferation in the Jimpy Mutant
}

\author{
Qian Wu, ${ }^{1}$ Robert H. Miller, ${ }^{3}$ Richard M. Ransohoff, ${ }^{1}$ Shenandoah Robinson, ${ }^{3}$ Jie Bu, ${ }^{2}$ and Akiko Nishiyama ${ }^{1,2}$ \\ ${ }^{1}$ Department of Neurosciences, The Lerner Research Institute, Cleveland Clinic Foundation, Cleveland, Ohio, \\ 2Department of Physiology and Neurobiology, University of Connecticut, Storrs, Connecticut, and \\ ${ }^{3}$ Department of Neurosciences, Case Western Reserve University, Cleveland, Ohio
}

The dysmyelinating mutant jimpy (jp) arises from a point mutation in the mouse gene encoding proteolipid protein and is characterized by severe dysmyelination attributable to oligodendrocyte death. This mutant was used to investigate the regulation of oligodendrocyte progenitor proliferation in the postnatal spinal cord. At postnatal day 18, jp spinal cord contained a three- to eightfold greater number of proliferating oligodendrocyte progenitor cells than did wild-type (wt) spinal cord. Increased proliferation in jp spinal cord was accompanied by a twofold increase in the number of progenitor cells. Semiquantitative reverse transcriptase-PCR revealed no change in the level of mRNA encoding the platelet-derived growth factor A, transforming growth factor- $\beta$, or insulin-like growth factor-I, all of which have been implicated as regulators of proliferation and differentiation of oligodendrocyte progenitor cells. There

Oligodendrocytes are generated from progenitor cells that arise in the ventral ventricular zone of the embryonic rodent spinal cord (Warf et al., 1991; Pringle and Richardson, 1993). These progenitor cells proliferate and migrate to occupy the entire CNS by the end of the first postnatal week (Hirano and Goldman, 1988; Pringle et al., 1992; Pringle and Richardson, 1993; Timsit et al., 1995; Nishiyama et al., 1996a). Platelet-derived growth factor (PDGF) AA is secreted by astrocytes and neurons and stimulates oligodendrocyte progenitor cell (OPC) proliferation via its $\alpha$ receptor (PDGF $\alpha \mathrm{R}$ ) (Raff et al., 1988; Richardson et al., 1988; Sasahara et al., 1991; Yeh et al., 1991). PDGF AA may be primarily responsible for establishing the number of OPCs in prenatal and early postnatal mouse spinal cord (Calver et al., 1998).

PDGF $\alpha \mathrm{R}$ is coexpressed with the NG2 proteoglycan on OPCs in vitro and in vivo, but both molecules are lost as the progenitors

Received May 18, 1999; revised Jan. 21, 2000; accepted Jan. 27, 2000.

This work was supported by National Institutes of Health Grants NS 35136 to A.N. and NS 30800 to R.H.M. and by the National Multiple Sclerosis Society Research Grant RG 2826 to A.N. We thank Dr. Judy Drazba (Cleveland Clinic, Cleveland, $\mathrm{OH}$ ) for her help with confocal microscopy and Drs. Bruce Trapp and Wendy Macklin (Cleveland Clinic) for helpful discussion. We thank Drs. William Stallcup (The Burnham Institute, La Jolla, CA), Joel Levine (State University of New York, Stony Brook, NY), Tom Hamilton (Cleveland Clinic), Carl-Henrik Heldin (Uppsala, Sweden), and Toshiro Kumanishi (Niigata University, Niigata, Japan) for antibodies.

Parts of this paper have been presented previously at the Keio University Symposia for Life Science and Medicine, Tokyo, December, 1997, and the 1091st Meeting of the Keio Medical Society, Tokyo, June, 1998.

Correspondence should be addressed to Dr. Akiko Nishiyama, Department of Physiology and Neurobiology, University of Connecticut, 3107 Horsebarn Hill Road, U-4156, Storrs, CT 06269-4156. E-mail: nishiyama@oracle.pnb.uconn.edu.

Copyright (C) 2000 Society for Neuroscience $0270-6474 / 00 / 202609-09 \$ 15.00 / 0$ was, however, a 17-fold increase in the level of mRNA encoding the chemokine GRO-1 and a 5- to 6-fold increase in GRO-1 protein in the jp spinal cord. Double immunofluorescence labeling revealed elevated levels of GRO-1 in reactive astrocytes in $j p$ spinal cord white matter. In vitro studies indicated that extracts from $j p$ spinal cord stimulated oligodendrocyte progenitor proliferation. Furthermore, removal of GRO-1 from jp extracts by immunoprecipitation reduced the proliferation of progenitor cells to a level similar to that achieved by wt extracts. These findings suggest a novel mechanism by which proliferation of oligodendrocyte progenitor cells is regulated in the postnatal spinal cord in response to insult.

Key words: oligodendrocyte progenitor; jimpy; glia; myelin; chemokine; GRO-1; NG2; PDGF; PDGF receptor differentiate into mature oligodendrocytes (Levine et al., 1993; Levine and Nishiyama, 1996; Nishiyama et al., 1996a, b). The NG2 proteoglycan forms a multimolecular complex that includes PDGF $\alpha \mathrm{R}$ and enhances OPC proliferation (Nishiyama et al., 1996b).

Further modulation of the proliferative response of OPCs to PDGF was recently described by Robinson et al. (1998), who demonstrated that the chemokine GRO-1 has a synergistic effect on PDGF-driven OPC proliferation. Chemokines (chemoattractant cytokines) are a family of small, secreted proteins that function as chemoattractants for leukocytes via G-proteincoupled seven-transmembrane receptors (Rollins, 1997; Luster, 1998). GRO-1 belongs to the CXC family of chemokines and includes molecules identified previously as mouse $\mathrm{KC}$ (Cochran et al., 1983; Oquendo et al., 1989), hamster GRO- $\alpha$ (Anisowicz et al., 1987), and human melanoma growth-stimulating activity (MGSA) (Richmond et al., 1988). These chemokines are considered to be homologs (see web site http://cytokine.medic. kumamoto-u.ac.jp/CFC/CK/CXCG/CXCG.html for a review of the nomenclature).

The proliferation and survival of oligodendrocyte lineage cells are significantly altered in jimpy $(j p)$ mutants. $J p$ is an X-linked recessive mutation in the proteolipid protein (PLP) gene (Nave et al., 1986, 1987; Ikenaka et al., 1988). White matter tracts of the affected males show dysmyelination accompanied by increased proliferation of morphologically identified immature oligodendrocytes (Skoff, 1982) and increased oligodendrocyte death (Knapp et al., 1986), possibly attributable to abnormal PLP transport and accumulation (Gow et al., 1998).

To define oligodendrocyte lineage cell proliferation and mo- 
lecular changes in jp spinal cord, we compared oligodendrocyte progenitor NG2-immunoreactive $(\mathrm{NG} 2+)$ cell number and proliferation in $j p$ and wild-type (wt) mouse spinal cord. We show increased proliferation of $\mathrm{NG} 2+$ cells in $j p$ spinal cord white matter compared with that in $w t$ spinal cord. Although no change was detected in the level of mRNA encoding PDGF A, transforming growth factor (TGF)- $\beta 2$ or $-\beta 3$, or insulin-like growth factor-I (IGF-I) in jp spinal cord, there was a significant increase in the expression of the chemokine GRO-1, which was present in $j p$ astrocytes. Furthermore, extracts from $j p$ spinal cord enhanced OPC proliferation in vitro, whereas extracts from $w t$ spinal cord had no effect. The growth-stimulatory activity in jp extracts could be eliminated by immunodepleting GRO-1 from the extracts. These data suggest that in addition to classical peptide growth factors, chemokines, which are synthesized in the CNS, contribute to the regulation of OPC proliferation in the postnatal spinal cord in response to insult.

\section{MATERIALS AND METHODS}

Animals. Heterozygous female mice $\left(\mathrm{Ta} \mathrm{Plp} \mathrm{j}^{\mathrm{jp}} /++\right)$ carrying the $j p$ mutation and $w t$ males (B6CBACa-A ${ }^{\mathrm{W}-\mathrm{J}} / \mathrm{A}$ F1) were obtained from The Jackson Laboratory (Bar Harbor, ME) and used as breeding pairs. At postnatal day 18 (P18), jp males were identified by their characteristic tremor. Unaffected male littermates were used as controls.

Sprague Dawley rats were obtained from Charles River Laboratories (Raleigh, NC). Newborn (P0-P2) rats were used to isolate oligodendrocyte progenitor cells.

Antibodies. Antibodies were obtained from the following sources. Rabbit anti-rat NG2 antibodies were gifts from Drs. William Stallcup (The Burnham Institute, La Jolla, CA) and Joel Levine (State University of New York, Stony Brook, NY). Rabbit anti-human PDGF $\alpha$ R (R7) antibody was a gift from Dr. Carl-Henrik Heldin (Uppsala, Sweden). Monoclonal antibodies to bovine glial fibrillary acidic protein (GFAP), S100 $\beta$, and GRO- $\alpha$ were obtained from Sigma (St. Louis, MO). Rabbit anti-bovine GFAP antibody was obtained from Dako (Carpinteria, CA). Mouse monoclonal antibody to 5-bromo-2'-deoxyuridine (BrdU) was obtained from Amersham (Arlington Heights, IL). Rabbit anti-bovine $\mathrm{S} 100 \beta$ was a gift from Dr. Toshiro Kumanishi (Niigata University, Niigata, Japan). Rat monoclonal antibodies to mouse F4/80 and CD45 were obtained from Accurate Chemicals (Westbury, NY). Rat monoclonal anti-mouse KC antibody was obtained from R \& D Systems (Minneapolis, MN). Rabbit anti-mouse KC antibody was a gift from Dr. Tom Hamilton (Cleveland Clinic, Cleveland, $\mathrm{OH}$ ).

BrdU labeling. To identify proliferating cells, $0.05 \mathrm{mg}$ of BrdU (Boehringer Mannheim, Indianapolis, IN)/gm of body weight was injected intraperitoneally into P18 mice three times at $2 \mathrm{hr}$ intervals. Two hours after the final injection, mice were perfused with $2 \%$ paraformaldehyde solution containing $0.01 \mathrm{M}$ sodium metaperiodate and $0.1 \mathrm{~m}$ lysine (paraformaldehyde-lysine-periodate fix). Brains and spinal cords were postfixed overnight in the same fixative. After cryoprotection in $0.1 \mathrm{M}$ phosphate buffer, $\mathrm{pH} 7.3$, containing $15 \%$ sucrose, the tissues were embedded in OCT compound. Ten micrometer sections were cut using a cryostat (Jung Frigocut 2800N; Leica, Nussloch, Germany) and processed for immunohistochemistry. Some sections were stained with hematoxylin and eosin.

Immunohistochemistry. For immunoperoxidase labeling, sections were rinsed in PBS and incubated in $1 \%$ hydrogen peroxide $\left(\mathrm{H}_{2} \mathrm{O}_{2}\right)$ to block endogenous peroxidase activity. Nonspecific protein-binding sites were blocked by incubation in PBS containing 5\% normal goal serum (Life Technologies, Grand Island, NY) for $1 \mathrm{hr}$ at room temperature. Sections were then incubated in primary antibodies diluted in 5\% normal goat serum overnight at $4^{\circ} \mathrm{C}$. Irrelevant primary antibodies were used as controls. After rinsing for $1 \mathrm{hr}$ in PBS, sections were incubated in biotinylated secondary antibodies (Vector Laboratories, Burlingame, $\mathrm{CA}$; diluted 1:500) for $1 \mathrm{hr}$ at room temperature followed by incubation in avidin-biotin complex conjugated with horseradish peroxidase (Vector Laboratories; diluted 1:1000) for $1 \mathrm{hr}$ at room temperature. Peroxidase activity was visualized by incubation in $0.1 \% 3,3^{\prime}$-diaminobenzidine and $0.03 \% \mathrm{H}_{2} \mathrm{O}_{2}$.

For double-immunofluorescent labeling, the two primary antibodies and secondary antibodies (Jackson ImmunoResearch, West Grove, PA) were applied to the sections simultaneously. Labeled sections were mounted in Vectashield (Vector Laboratories) and examined using a Zeiss Axiophot or Leica DMR epifluorescence microscope or a Leica TCS-NT confocal laser-scanning microscope.

For detection of $\mathrm{BrdU}$, sections were pretreated with $2 \mathrm{~N} \mathrm{HCl}$ at room temperature for $10 \mathrm{~min}$ followed by neutralization in $0.1 \mathrm{M}$ sodium borate buffer, $\mathrm{pH} 8.2$, at room temperature for $10 \mathrm{~min}$. After washes in PBS, the sections were processed for double immunohistochemistry as described above.

Cell counts. The number of cells double-labeled for NG2 and BrdU was estimated in the white matter of $w t$ and $j p$ spinal cord at P18 by counting double-labeled cells in the white matter of $10 \mu \mathrm{m}$ transverse sections at cervical, thoracic, and lumbar levels. Areas of the spinal cord white matter in which cells were counted were measured by use of the NIH Image program. Three to five sections from each tissue were counted, and mean values were obtained for each tissue. A total of four to six $w t$ and $j p$ mice were analyzed. The numbers are expressed as the numbers of $\mathrm{NG} 2+/ \mathrm{BrdU}+$ cells per unit area of spinal cord white matter, which includes dorsal, lateral, and anterior columns. Only cells with BrdU staining over the entire nucleus surrounded by a closed ring of NG2 immunoreactivity were scored as NG2+/BrdU+ (see Fig. 2A,B). Cells with one or two small puncta of BrdU immunoreactivity or BrdU+ cells that were only partially surrounded by NG2 immunoreactivity were not scored as positive.

The number of OPCs in the dorsal column and dorsal horn of $j p$ and $w t$ spinal cord was estimated by counting the number of PDGF $\alpha$ Rimmunoreactive cells in immunoperoxidase-labeled sections. Cell bodies with a distinct ring of PDGF $\alpha \mathrm{R}$ immunoreactivity were scored as positive. The area of the dorsal column and dorsal horn was estimated by use of the NIH Image program.

Reverse transcriptase-PCR. Total RNA was isolated from P18 jp and $w t$ spinal cords using the guanidinium isothiocyanate method (Chirgwin et al., 1979). Five micrograms of total RNA were used in the reverse transcriptase (RT) reaction using SuperScript II (Life Technologies). One-tenth of the synthesized cDNA was subjected to PCR in $100 \mu \mathrm{l}$ containing $0.2 \mu \mathrm{Ci}$ of $\left[\alpha^{-32} \mathrm{P}\right] \mathrm{dCTP}$ (New England Biolabs, Beverly, MA). The primers used were as follows: mouse PDGF A, forward, $5^{\prime}$-ctgtg cccat tcgca gg, and reverse, $5^{\prime}$-accgc acgca cattg (Mercola et al., 1990); mouse TGF- $\beta 2$, forward, $5^{\prime}$-ttcac cacaa agaca gg, and reverse, $5^{\prime}$-tttcc atcca agatc cc (Miller et al., 1989a); mouse TGF- $\beta 3$, forward, $5^{\prime}$-ttcga catga tccag gg, and reverse, $5^{\prime}$-gcgga agcag taatt gg (Miller et al., 1989b); mouse IGF-I, forward, 5'-acctg gcgct ctgct tgc, and reverse, 5 '-tgggc atgtc agtgt ggc (Bell et al., 1986); mouse KC, forward, 5'-tgcac ccaaa ccgaa gtcatag, and reverse, $5^{\prime}$-gtggt tgaca cttag tggtc tc (Oquendo et al., 1989); and mouse cyclophilin, forward, $5^{\prime}$-cgtgg getcc gtcgt cttcc tt, and reverse, $5^{\prime}$-ccggc tgtct gtctt ggtgc tctc (Hasel et al., 1991). Amplified products were separated on $6 \%$ polyacrylamide gels containing $8 \mathrm{M}$ urea. After electrophoresis, the gels were dried and exposed to x-ray film for autoradiography or to a phosphoimager screen for quantitation of the density of the bands.

The optimal amplification cycle number for PCR was determined to ensure that the amount of amplified product was proportional to the amount of input cDNA for both abundant (cyclophilin) and less abundant (TGF- $\beta 2$ ) mRNA species. To quantify the relative amount of mRNA encoding each growth factor, we normalized the density of the bands to that of cyclophilin mRNA. The mean values for each growth factor were obtained from 3 to $5 w t$ and $j p$ RNA samples.

Tissue extracts. Spinal cords from $w t$ and $j p$ mice were homogenized in DMEM $\left(300 \mu \mathrm{l} / \mathrm{spinal}\right.$ cord), extracted at $4^{\circ} \mathrm{C}$ for $15 \mathrm{~min}$, and centrifuged at 13,000 rpm for $5 \mathrm{~min}$ to remove insoluble material. GRO-1 was immunodepleted from the extracts by immunoprecipitating sequentially with rabbit and rat anti-mouse KC antibodies (obtained from Dr. Tom Hamilton, Cleveland Clinic, and R \& D Systems, respectively). Control immunodepletion was performed using rabbit anti- $\beta$-galactosidase (anti- $\beta$-gal) antibody or normal rabbit serum. Antigen-antibody complexes were precipitated using protein A-Sepharose (Pharmacia, Piscataway, NJ). Supernatants were concentrated using Microcon concentrators ( $3 \mathrm{kDa}$ cutoff; Millipore, Bedford, MA). The protein concentration of each fraction was assayed using the Lowry method (Bio-Rad, Hercules, CA). The levels of GRO-1 in the extracts were assayed by ELISA using polyclonal antibodies to mouse $\mathrm{KC}$, according to the instructions provided by the manufacturer ( $\mathrm{R} \& \mathrm{D}$ Systems). Equal amounts of protein were added to cultures of oligodendrocyte progenitor cells.

Cultures of oligodendrocyte progenitor cells. OPCs were isolated and purified from neonatal rat spinal cords by immunopanning with A2B5 

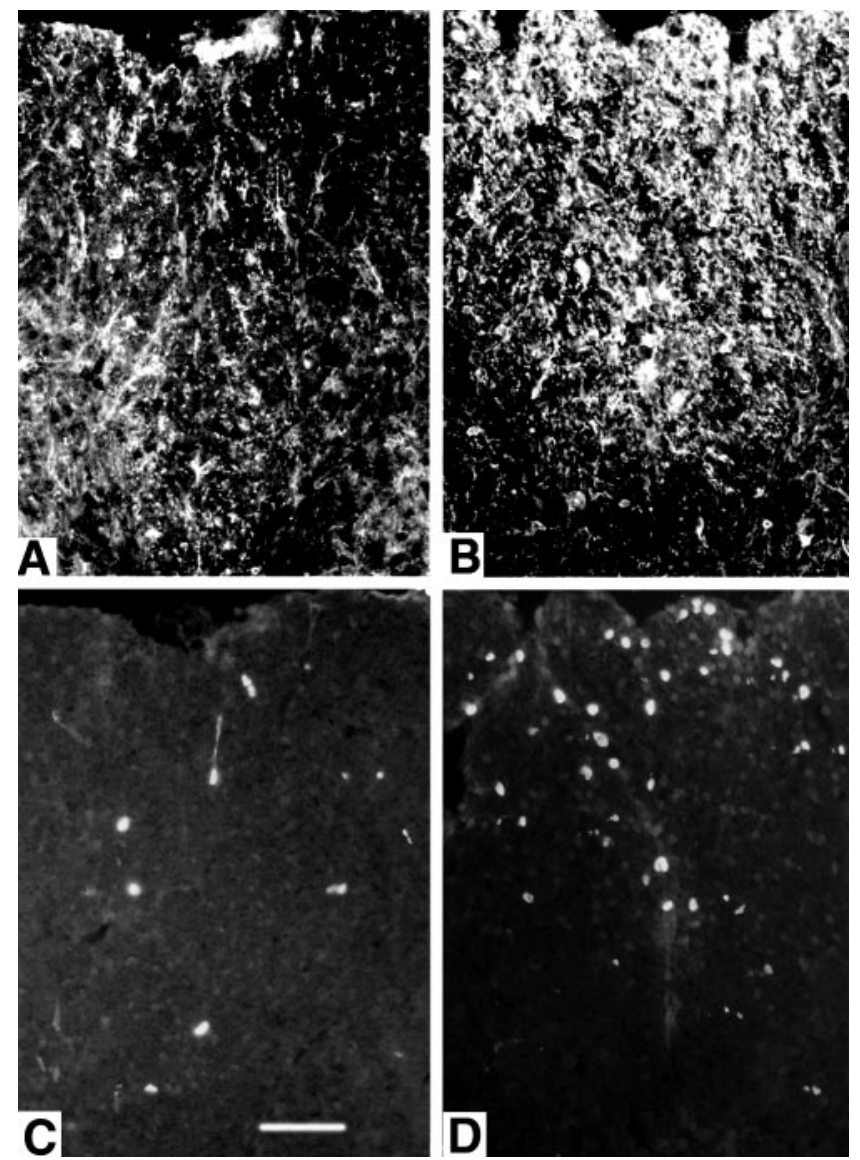

Figure 1. Double-immunofluorescence labeling for $\operatorname{NG} 2(A, B)$ and $\operatorname{BrdU}(C, D)$ in the dorsal column of $w t(A, C)$ and $j p(B, D)$ spinal cord at P18. A greater number of cells has incorporated BrdU in $j p$ white matter than in $w t$ white matter. There is increased immunoreactivity for NG2 in $j p$ spinal cord compared with $w t$ spinal cord. Scale bar, $50 \mu \mathrm{m}$.

monoclonal antibody as described by Robinson and Miller (1996). Immunocytochemistry of purified cells revealed the population to be $95 \%$ homogeneous for $\mathrm{A} 2 \mathrm{~B} 5+$ and $\mathrm{NG} 2+$ cells. Contaminating GFAP+ astrocytes comprised $4-5 \%$ of the population, whereas microglia constituted $<1 \%$ of the population. Cells were plated in 48 -well plates at a density of 80,000 cells/well. After $18 \mathrm{hr}$, the medium was changed to serum-free DMEM containing N2 supplement (Life Technologies), PDGF AA, and $j p$ or $w t$ extracts. Forty-eight hours later, $0.5 \mu \mathrm{Ci}$ of $\left[{ }^{3} \mathrm{H}\right]$ thymidine (NEN Life Science Products, Boston, MA) was added to each well. After a labeling period of $4 \mathrm{hr}$, cells were washed twice with PBS, washed twice with cold 5\% trichloroacetic acid, and lysed with $0.02 \mathrm{M} \mathrm{KOH}$, and radioactivity was measured using a scintillation counter. In some experiments, cells were plated on glass coverslips in 24-well plates in the presence of control or GRO-1-immunodepleted jp extracts, labeled with $\mathrm{BrdU}$, and assayed for the percentage of $\mathrm{A} 2 \mathrm{~B} 5+$ cells that had incorporated BrdU as described previously (Robinson et al., 1998).

\section{RESULTS}

\section{Increased progenitor proliferation in jp spinal cord}

OPC proliferation was examined in spinal cords of P18 wt and jp mice. P18 represents an age past the peak in oligodendrogenesis, when myelination has occurred at all levels of the spinal cord, and thus OPC proliferation is expected to have declined to a low level in $w t$ mice. Because $j p$ is an $\mathrm{X}$-linked recessive mutation, $w t$ and jp males were used for all the analyses.

BrdU labeling revealed a significant increase in the number of proliferating cells in white matter tracts of the $j p$ spinal cord
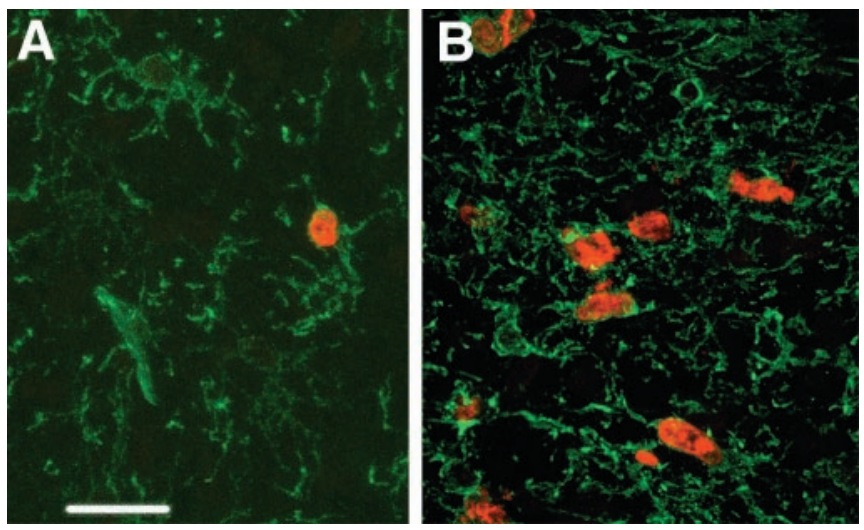

Figure 2. Confocal laser-scanning images of a section through P18 wt $(A)$ and jp $(B)$ spinal cord double-labeled for BrdU (red) and NG2 (green). The majority of BrdU+ nuclei are surrounded by NG2+ cell bodies and processes, indicating localization of BrdU and NG2 in the same cells. Scale bar, $30 \mu \mathrm{m}$.

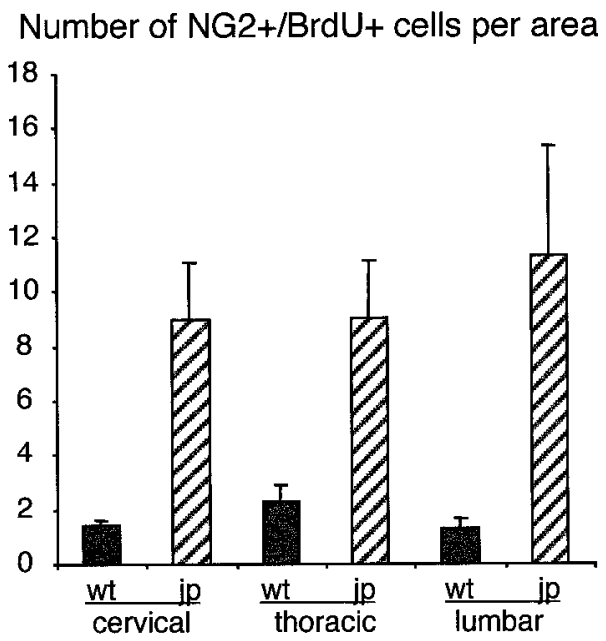

Figure 3. The number of BrdU+/NG2+ cells in wt (filled bars) and $j p$ (hatched bars) spinal cord. The numbers represent the number of doublelabeled cells per unit area of white matter in a $10-\mu \mathrm{m}$-thick transverse section from cervical, thoracic, and lumbar spinal cord. Error bars represent SD $(n=4)$. There is a three- to eightfold increase in the number of $\mathrm{BrdU}+/ \mathrm{NG} 2+$ cells in $j p$ spinal cord.

(Fig. 1). The vast majority of cells that incorporated BrdU were NG2+-presumptive OPCs (Fig. 2). In wt spinal cord 90-95\% of the BrdU+ cells were $\mathrm{NG} 2+$, whereas only $70-80 \%$ of the $\mathrm{BrdU}+$ cells in the $j p$ spinal cord were $\mathrm{NG} 2+$. It is likely that 20-30\% of BrdU + cells that were NG2-negative in jp spinal cord represent locally proliferating microglia (Vela Hernandez et al., 1997). To determine the extent of the increase in NG2+ cell proliferation in jp spinal cord, we estimated the number of $\mathrm{BrdU}+/ \mathrm{NG} 2+$ cells per unit area of white matter in cervical, thoracic, and lumbar spinal cord. The number of $\mathrm{NG} 2+$ cells undergoing DNA synthesis was three- to eightfold higher in all three segments of jp spinal cord compared with that of $w t$ spinal cord (Fig. 3). In jp spinal cord the increased BrdU incorporation in NG2+ cells was seen only in white matter, although NG2+ cells were present in both white and gray matter. Within white matter, NG2 + cells in jp spinal cord appeared to have increased numbers of processes and elevated levels of NG2 immunoreactivity (Figs. $1 A, B, 2)$. 

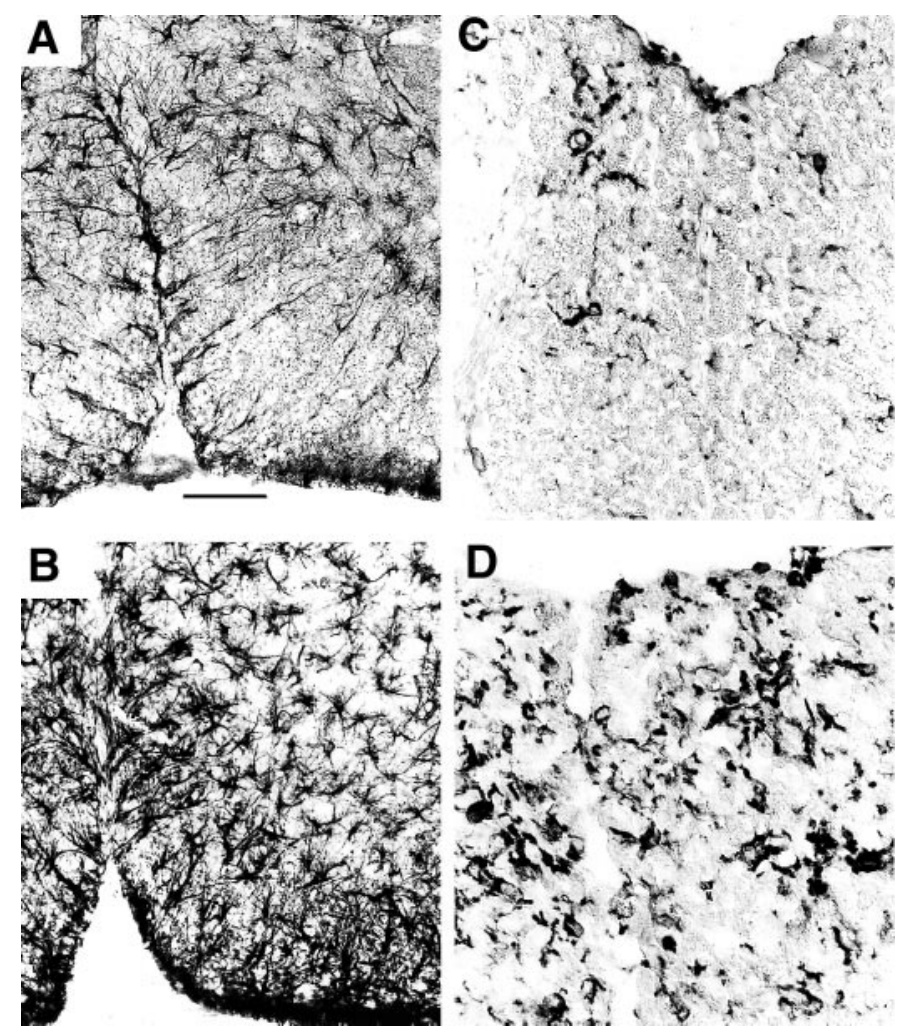

Figure 4. Immunoperoxidase labeling for $\operatorname{GFAP}(A, B$; rabbit antibovine GFAP) and the microglial antigen $\mathrm{F} 4 / 80(C, D)$ in $w t(A, C)$ and $j p$ $(B, D)$ spinal cord at P18. $A, B$, There is increased intensity of GFAP immunoreactivity in astrocytes in the anterior column of $j p$ spinal cord. $C$, $D$, There is an increase in the number of F4/80+ microglial cells and increased intensity of immunoreactivity of cells in the $j p$ dorsal column. Scale bar, $50 \mu \mathrm{m}$.

\section{Astrogliosis and microglial activation in jp spinal cord}

Previous studies demonstrated astrogliosis and microglial activation in jp spinal cord, and these observations were confirmed in the present study. Jp spinal cord exhibited elevated GFAP immunoreactivity compared with that of $w t$ (Fig. 4A,B), which appeared to be primarily a result of hypertrophy rather than elevated astrocyte cell number. A significant increase in the number of microglial cells labeled with an antibody to the microglia- and macrophage-specific integral membrane protein F4/80 (Austyn and Gordon, 1981; McKnight et al., 1996) was seen in jp compared with $w t$ spinal cords (Fig. 4C,D). Together these data suggest that there is a widespread activation and proliferation of macroglia and microglia in jp spinal cord.

\section{Increased numbers of oligodendrocyte progenitor cells in $j p$ spinal cord}

To determine whether the increased proliferation of NG2+ cells in jp spinal cord was accompanied by increased numbers of OPCs, progenitor cell numbers were estimated by counting PDGF $\alpha \mathrm{R}$ immunoreactive cells. PDGF $\alpha \mathrm{R}$ immunoreactivity was used because NG2 + cells in the postnatal CNS parenchyma express PDGF $\alpha \mathrm{R}$ (Nishiyama et al., 1996a, 1997) and PDGF $\alpha \mathrm{R}$ is detected more prominently on cell bodies than is NG2, whereas NG2 is localized on processes as well as cell bodies. There was a greater number of PDGF $\alpha \mathrm{R}+$ cells in the white matter of $j p$ spinal cord compared with $w t$, and the individual cells were more intensely labeled (Fig. 5A,B). Quantitation of cell number dem-
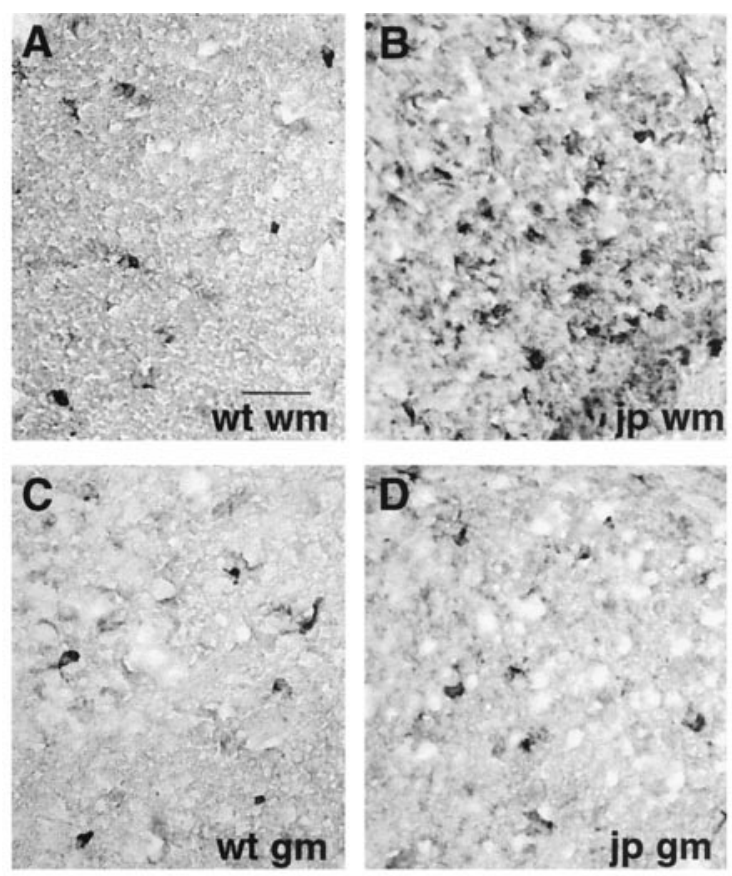

\section{E. Number of PDGF R+ Cells}

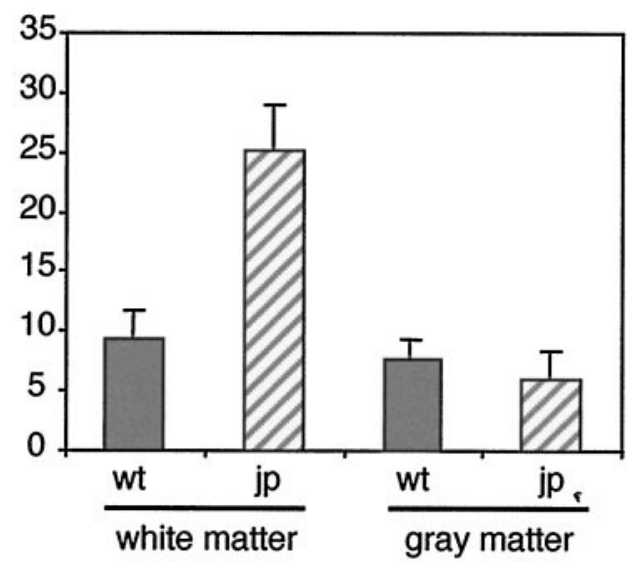

Figure 5. $A-D$, Immunoperoxidase labeling for PDGF $\alpha \mathrm{R}$ in the dorsal column $(w m ; A, B)$ and dorsal horn $(g m ; C, D)$ of $w t(A, C)$ and $j p(B, D)$ cervical spinal cord at P18. There is an increased number of PDGF $\alpha \mathrm{R}+$ cells in jp dorsal column but not dorsal horn. Scale bar, $50 \mu \mathrm{m}$. E, Number of PDGF $\alpha$ R-immunoreactive cells per unit area in the cervical dorsal column (white matter) and dorsal horn (gray matter) of $w t$ and $j p$ spinal cord at P18. Error bars represent SD $(n=3)$. gm, Gray matter; wm, white matter.

onstrated a 2.5-fold increase in PDGF $\alpha \mathrm{R}+$ cells in the jp dorsal column compared with those in the $w t$ cervical dorsal column (Fig. $5 E$ ). In the gray matter, there was no significant difference in the number of PDGF $\alpha \mathrm{R}+$ cells between $w t$ and $j p$ (Fig. 5C-E). These data indicate that the elevated level of progenitor proliferation in the white matter of $j p$ spinal cord is accompanied by elevated numbers of progenitor cells.

The levels of PDGF-A, IGF-I, and TGF- $\beta$ mRNA are not altered in jp spinal cord

Several growth factors are known to modulate the proliferation of OPCs. To understand the mechanism for enhanced OPC proliferation in jp, we examined by semiquantitative RT-PCR the levels of mRNA encoding these growth factors. 


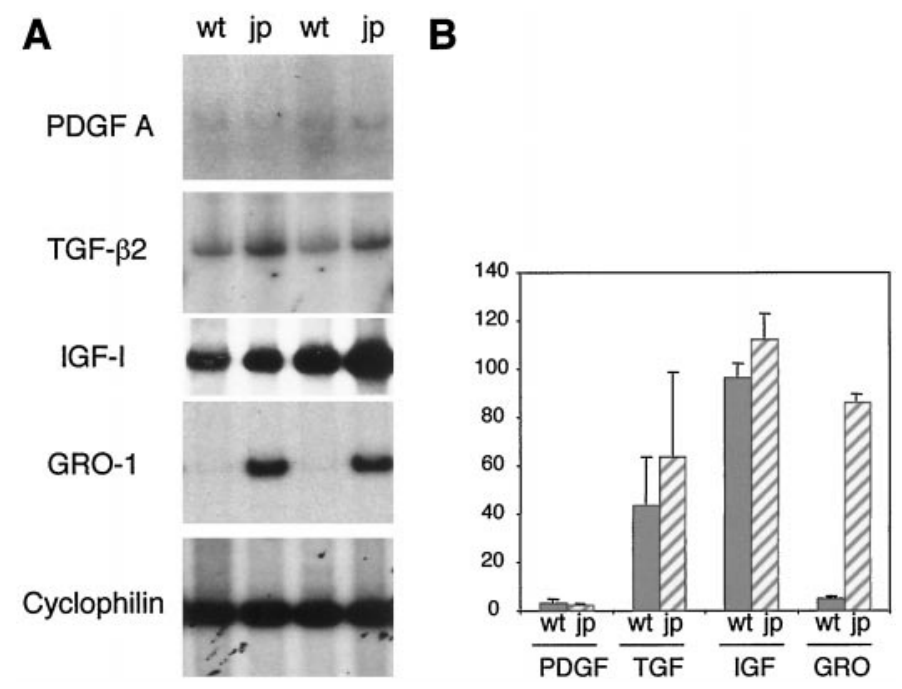

Figure 6. Semiquantitative RT-PCR to compare PDGF A, TGF- $\beta 2$, IGF-I, and GRO-1 mRNA levels between $w t$ and $j p$ spinal cord. $A$, Representative results of RT-PCR using $5 \mu \mathrm{g}$ of total RNA from P18 $w t$ or $j p$ spinal cord and oligonucleotide primers for PDGF A chain, TGF- $\beta 2$, IGF-I, GRO-1 (mouse KC), and cyclophilin. Each lane represents RNA extracted from one spinal cord. $B$, Quantitation of the intensity of the bands in $A$ using a phosphoimager. The values represent the intensity of the bands for PDGF A, TGF- $\beta 2$, IGF-I, and GRO- 1 mRNA normalized to the intensity of the bands for cyclophilin mRNA. Error bars represent $\mathrm{SD}(n=3)$. There is no significant difference in the amount of PDGF A, TGF- $\beta 2$, or IGF-I mRNA between $w t$ and $j p$ spinal cord. There is a 17 -fold increase in GRO-1 mRNA in $j p$ spinal cord.

There was no significant increase in the level of PDGF A mRNA in jp spinal cord at P18 compared with that in $w t$ spinal cord (Fig. 6). Relatively low levels of PDGF A mRNA were expressed in both $j p$ and $w t$ spinal cord. Similarly, there was no significant difference in the level of mRNA encoding IGF-I (Fig. 6), another putative oligodendrocyte progenitor cell mitogen (McMorris et al., 1986, 1988; Carson et al., 1993; Beck et al., 1995). These data suggest that increased OPC proliferation in jp spinal cord is not simply the result of elevated mitogen levels.

Members of the TGF- $\beta$ family are known to be present in the CNS (Unsicker et al., 1991) and inhibit OPC proliferation (McKinnon et al., 1993). To determine whether the enhanced proliferation seen in jp spinal cord reflected a reduction in inhibition, the relative levels of mRNA for TGF- $\beta 2$ and $-\beta 3$ were assayed. No significant decrease in the level of TGF- $\beta 2$ (Fig. 6) or $-\beta 3$ (data not shown) mRNA was detected in the jp spinal cord, although the level of TGF- $\beta 2$ mRNA was slightly increased in $j p$ compared with $w t$ spinal cord. These findings suggest that altered levels of well known oligodendrocyte lineage growth factors are unlikely to be responsible for the increase in proliferation of $\mathrm{NG} 2+$ cells in jp spinal cord.

\section{Expression of the chemokine GRO-1 is elevated in jp spinal cord}

The elevated levels of OPC proliferation and the normal levels of OPC mitogens in jp spinal cord suggest that additional mechanisms regulate local proliferation of OPCs. The chemokine GRO-1 has been shown to be expressed by spinal cord astrocytes and to stimulate proliferation of OPCs (Robinson et al., 1998). To determine whether elevated levels of GRO-1 expression correlated with the increased proliferation of OPCs in jp spinal cord, the level of mRNA for GRO-1 was compared in jp and $w t$ spinal cord using oligonucleotide primers derived from the mouse GRO-1 (identified previously as KC) cDNA sequence (Oquendo et al., 1989). There was a 17-fold higher level of GRO-1 mRNA in P18 jp spinal cord compared with that in $w t$ spinal cord (Fig. 6). Thus, the elevated OPC proliferation in jp spinal cord correlated with elevated levels of GRO-1 mRNA. In contrast to the elevated levels of GRO-1 mRNA in jp spinal cord, the levels of GRO-1 mRNA in $j p$ cerebrum containing corpus callosum were not significantly higher than those in $w t$ cerebrum (data not shown).

To determine whether increased GRO-1 mRNA in jp spinal cord was accompanied by increased levels of GRO-1 protein, the GRO-1 content in spinal cord extracts was measured by ELISA. Table 1 shows a representative result of an ELISA assay, which demonstrates a five- to sixfold increase in GRO-1 in jp spinal cord extracts compared with that in $w t$ extracts (wt, $4.24 \mathrm{pg}$ of GRO-1/mg of protein; jp, $25.1 \mathrm{pg}$ of GRO-1/mg of protein). This finding is consistent with the results of Western blotting using rat anti-mouse GRO-1 antibody (data not shown). Because antibodies to GRO-1 recognize the antigen only under nonreducing conditions, we failed to detect GRO-1 monomer on Western blots. The high-molecular weight immunoreactive material on Western blots had an electrophoretic mobility similar to that of purified GRO-1 under nonreducing conditions, suggesting that the antibodies used in these studies reacted specifically with GRO-1.

\section{GRO-1 is present in astrocytes}

In normal developing rat spinal cord, GRO-1 is expressed in astrocytes in a spatially and temporally regulated manner (Robinson et al., 1998). To determine whether the elevated levels of GRO-1 seen in jp spinal cord were astrocyte-derived, sections of spinal cord were double-labeled with antibodies to GRO-1 and GFAP or S100 $\beta$. In $w t$ spinal cord at P18, low levels of GRO-1 were detected in scattered cells in the dorsal columns (Fig. 7A). In parallel sections from jp spinal cord there were elevated levels of GRO-1 immunoreactivity in cell bodies and a more diffuse punctate staining throughout the neuropil, suggesting an extracellular localization of the chemokine (Fig. 7B). Double-labeling studies revealed that GRO-1 was present in GFAP + astrocytes (Fig. 8A-C). Because GFAP immunoreactivity was primarily localized in astrocyte processes whereas the chemokine was localized in the cell body, colocalization studies were repeated using antibodies to $\mathrm{S} 100 \beta$, a calcium-binding protein expressed by astrocytes (Kligman and Hilt, 1988). Figure $8 D-F$ demonstrates that GRO-1 is expressed in $\mathrm{S} 100 \beta+$ astrocytes.

Table 1. ELISA for GRO-1 levels in $w t$ and $j p$ spinal cord extracts

\begin{tabular}{lc} 
& $\begin{array}{c}\text { GRO-1/protein } \\
(\mathrm{pg} / \mathrm{mg})\end{array}$ \\
\hline$w t$ total & 4.24 \\
$j p$ total & 25.06 \\
$w t$ GRO-depleted & 2.81 \\
$w t \beta$-gal-depleted & 6.36 \\
$j p$ GRO-depleted & 10.93 \\
$j p$-gal-depleted & 32.91 \\
\hline
\end{tabular}

This is a representative set of results from three experiments, which showed an average of 6.9-fold higher GRO-1 concentration in jp extracts compared with that in $w t$ extracts. Immunodepletion of GRO-1 from $j p$ extracts (jp GRO-depleted) resulted in a 2.3- to 3.3-fold reduction in the concentration of GRO-1. 

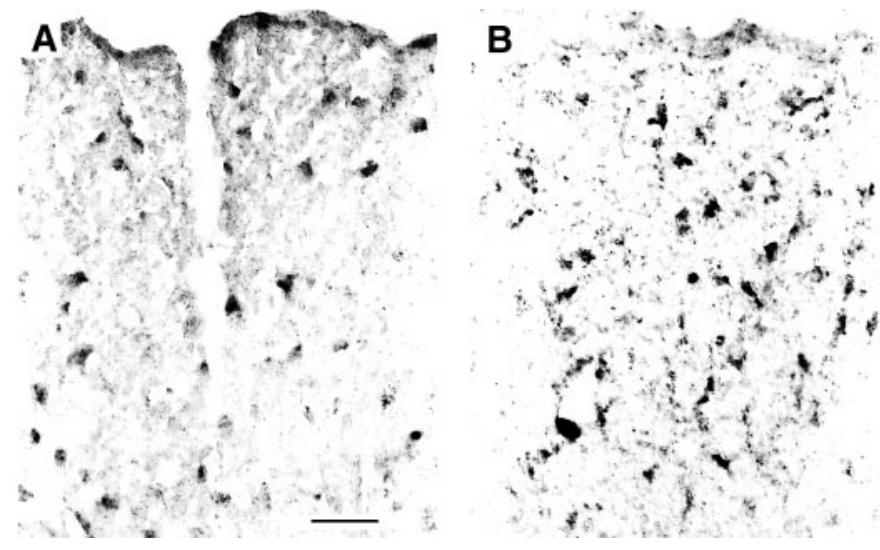

Figure 7. Immunoperoxidase labeling for GRO-1 in $w t(A)$ and $j p(B)$ spinal cord at P18, using mouse anti-human GRO-1 antibody (Sigma). There is increased immunoreactivity for GRO-1 in the jp dorsal column. Punctate GRO-1 immunoreactivity that is not associated with cells is more pronounced in $j p$ cord. Scale bar, $50 \mu \mathrm{m}$.
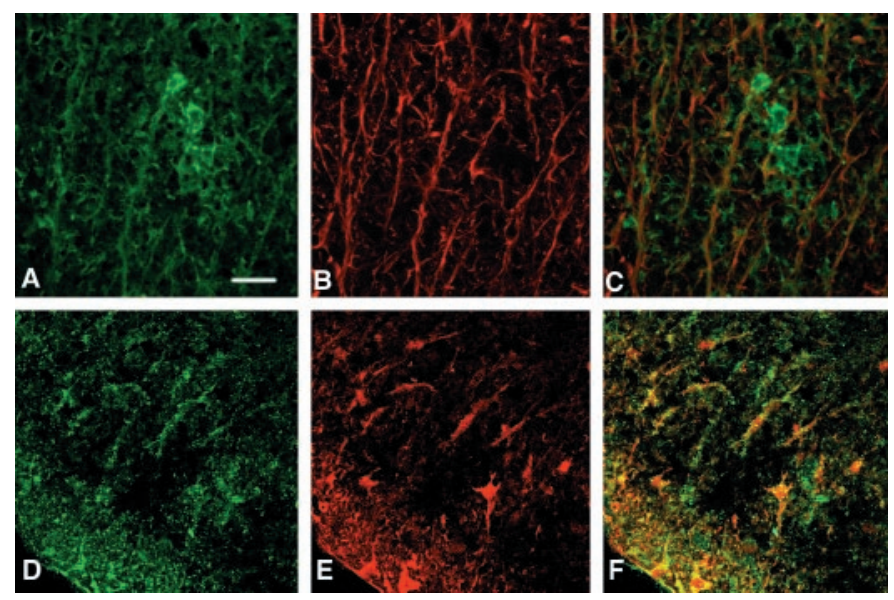

Figure 8. Confocal laser-scanning images of sections through $\mathrm{P} 18 \mathrm{jp}$ spinal cord double-labeled for GFAP $(B, C$; rabbit anti-bovine GFAP antibody) and GRO-1 ( $A, C$; mouse anti-human GRO-1 antibody) or $\mathrm{S} 100 \beta(E, F)$ and GRO-1 $(D, F)$. GRO-1 is present in GFAP+ or $\mathrm{S} 100 \beta+$ astrocytes. Scale bar, $35 \mu \mathrm{m}$.

\section{Increased expression of GRO-1 in jp spinal cord does not result in neutrophil infiltration}

In other models of CNS pathogenesis, local increases in the expression of CXC chemokines such as GRO-1 result in local recruitment of neutrophils (Glabinski et al., 1997; Tani et al., 1996). Although jp spinal cord expressed elevated levels of GRO-1, there was no evidence of elevated recruitment of neutrophils into the spinal cord either by hematoxylin and eosin staining (data not shown) or by immunohistochemical analysis using an antibody to CD45, a leukocyte-specific receptor tyrosine phosphatase (data not shown). These data suggest that the influence of elevated levels of chemokines in the $j p$ spinal cord is restricted to the CNS.

\section{Jp spinal cord extracts stimulate progenitor proliferation}

Purified OPC cultures (Robinson et al., 1998) were used to compare the effects of extracts from P18 wt and jp spinal cords on OPC proliferation. Preliminary observations revealed a greater proliferation of OPCs in the presence of $j p$ extracts compared

\section{Effects of jp extracts on OPC proliferation}

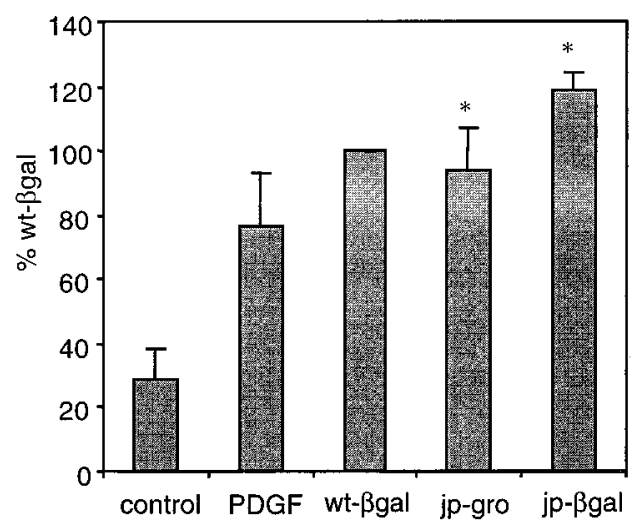

Figure 9. Effects of $w t$ and $j p$ spinal cord extracts on OPC proliferation. Control, Serum-free medium plus N2 supplement; PDGF, control plus $10 \mathrm{ng} / \mathrm{ml}$ PDGF AA; jp-gro, jp extracts immunodepleted of GRO-1 (300 $\mu \mathrm{g} / \mathrm{ml}$ protein); jp- $\beta g a l, j p$ extracts immunodepleted of $\beta$-galactosidase $(300 \mu \mathrm{g} / \mathrm{ml}$ protein); and $w t-\beta g a l$, $w t$ extracts immunodepleted of $\beta$-galactosidase $(300 \mu \mathrm{g} / \mathrm{ml}$ protein). All extracts were added in the presence of $10 \mathrm{ng} / \mathrm{ml}$ PDGF AA. $\left[{ }^{3} \mathrm{H}\right]$ thymidine incorporation was assayed $2 \mathrm{~d}$ after the addition of extracts. Numbers indicate the ratio of $\left[{ }^{3} \mathrm{H}\right]$ thymidine incorporation, measured in decays per minute, by OPCs under the indicated conditions to that in the presence of $j p$ - $\beta g a l$ extracts (expressed as a percent). They represent average percent values from three separate culture experiments, and triplicate measurements for $\left[{ }^{3} \mathrm{H}\right]$ thymidine incorporation were taken for each experiment. Error bars indicate SD. The difference in OPC proliferation by jp-gro and jp- $\beta g a l\left({ }^{*}\right)$ is significant at $p<0.03$ ( $t$ test).

with that in $w t$ extracts. To determine whether the growth stimulatory effect of $j p$ extracts was caused by GRO-1, we removed GRO-1 from $j p$ extracts by sequential immunoprecipitation using two different anti-mouse GRO-1 (KC) antibodies (obtained from R \& D Systems and Dr. Tom Hamilton). Cleared supernatants were assayed for GRO-1 by ELISA (Table 1) and added to OPC cultures. Table 1 shows a representative set of results of three immunoprecipitation experiments. Immunoprecipitation of $j p$ extracts with anti-GRO-1 antibodies (GRO-1-depleted) resulted in a 2.3- to 3.3-fold reduction in the concentration of GRO-1. However, the concentration of GRO-1 in jp extracts after two rounds of GRO-1 immunodepletion was more than twofold higher than that in total $w t$ extracts.

Addition of control $\beta$-gal-depleted extracts from jp spinal cords to OPC cultures resulted in increased cell proliferation (Fig. 9, $j p$ - $\beta g a l)$. Addition of GRO-1-depleted $j p$ extracts resulted in a level of OPC proliferation that was comparable with that observed with PDGF alone (Fig. 9, PDGF) or with $\beta$-gal-depleted extracts from $w t$ spinal cords (Fig. 9, wt- $\beta g a l$ ). Addition of GRO1-depleted $j p$ extracts resulted in an average $21.3 \%$ reduction in OPC proliferation compared with that in $\beta$-gal-depleted $j p$ extracts in three independent experiments. Furthermore, in the presence of control jp extracts ( $j p$ extracts precipitated with normal rabbit serum), $58 \%$ of A2B5+ cells incorporated BrdU, whereas $11 \%$ of $\mathrm{A} 2 \mathrm{~B} 5+$ cells incorporated $\mathrm{BrdU}$ in the presence of GRO-1-depleted jp extracts. These findings suggest that the enhanced OPC proliferation in $j p$ spinal cord is mediated in part by increased levels of GRO-1.

\section{DISCUSSION}

The proliferation of OPCs is tightly regulated during development. In normal mouse spinal cord the majority of oligodendro- 
cytes are generated and myelin formation is well established by the third postnatal week (Matthews and Duncan, 1971), and glial cell proliferation declines beyond this stage. Previous studies demonstrated enhanced proliferation of immature oligodendrocytes in jp spinal cord identified by morphological criteria (Skoff, 1982). The current studies support and extend these observations. The low levels of BrdU incorporation seen in NG2+ OPCs in $w t$ spinal cord, combined with the increased BrdU incorporation in jp spinal cord, strongly suggest that the NG2+ cells and previously morphologically defined immature oligodendrocytes represent overlapping cell populations. Quantitative analyses of NG2+ cell proliferation and the subsequent increase in the number of PDGF $\alpha \mathrm{R}+$ OPCs revealed an apparent discrepancy in the $j p$ spinal cord. Although the increase in BrdU incorporation was greatly elevated (three- to eightfold), the increase in the number of OPCs was significantly lower (2.5-fold). Several factors may explain the differences. OPCs may rapidly differentiate into oligodendrocytes in jp spinal cord and therefore lose expression of the progenitor markers NG2 and PDGF $\alpha$ R. In agreement with this hypothesis, a significantly higher proportion of BrdU+ nuclei in jp spinal cord had only a partial, rather than a complete, ring of NG2 immunoreactivity around them, possibly because of accelerated progenitor cell differentiation. Alternatively, NG2+ cells may themselves die immediately after incorporation of BrdU. Such cell death of OPCs in jp spinal cord would be consistent with the observation that oligodendrocyte lineage cells die before they express detectable levels of PLP (Vermeesch et al., 1990). However, the clearance of dead cells would have to be very rapid, because it is not morphologically obvious.

Cell death in jp spinal cord occurs relatively late in the oligodendrocyte lineage. The spinal cord of $j p$ animals is characterized by a reduced patchy presence of myelin. The reduction in myelin is directly correlated with a reduction in the number of differentiated oligodendrocytes in jp spinal cord compared with wt spinal cords (Kraus-Ruppert et al., 1973; Meier and Bischoff, 1975; Skoff, 1982). The reduction in the number of differentiated oligodendrocytes is even more dramatic in the context of the elevated levels of OPC proliferation that occur in jp spinal cord. Because the increase in proliferation of NG2+ cells is accompanied by an increase in the number of PDGF $\alpha \mathrm{R}+$ progenitor cells, the reduction in the number of differentiated oligodendrocytes must reflect cell death of late-stage progenitors or differentiated oligodendrocytes. This idea is consistent with morphological studies that have demonstrated that dying oligodendrocytes are more prevalent than dying progenitor cells in jp spinal cord (Skoff, 1982, 1995; Grinspan et al., 1998).

The elevation in OPC proliferation and death in jp animals is not uniform throughout the CNS. The increase in proliferation of $\mathrm{NG} 2+$ cells was more pronounced in the spinal cord than in the corpus callosum. This may reflect the chronology of OPC proliferation and myelination, which occur later in the corpus callosum than in the spinal cord (Matthews and Duncan, 1971; Sturrock, 1980; Skoff, 1982). Within the spinal cord, there was no significant increase in NG2+ cell proliferation in the gray matter, although $\mathrm{NG} 2+$ cells were abundant in both gray and white matter, suggesting that $\mathrm{NG} 2+$ cell proliferation in white and gray matter are regulated by different mechanisms. Consistent with this is our observation that OPC number is elevated in jp white matter but not gray matter. This raises the possibility that there are different lineages of oligodendrocytes in the CNS that are generated by different mechanisms, as suggested by recent studies of Spassky et al. (1998) and Marmur et al. (1998).
Studies in vitro and in vivo suggest that PDGF AA is a major mitogen for NG2+ OPCs (Raff et al., 1988; Richardson et al., 1988; Nishiyama et al., 1996b; Calver et al., 1998) and may regulate the final number of OPCs. The lack of elevation in PDGF A mRNA levels in jp spinal cord suggests that the enhanced proliferation in $j p$ is not simply a reflection of elevated PDGF. Likewise, there is no obvious alteration in the expression patterns of two other peptide growth factors, TGF- $\beta$ and IGF-I, both of which have been implicated in the regulation of proliferation and differentiation of OPCs (McMorris and Dubois-Dalcq, 1988; Carson et al., 1993; McKinnon et al., 1993; Beck et al., 1995). It seems likely that although these growth factors play a major role in regulating the initial production of oligodendrocytes and myelin, other mechanisms regulate the maintenance of myelin and oligodendrocyte numbers at later postnatal stages and in the mature CNS.

Several mechanisms have been demonstrated to regulate the proliferative response of OPCs to PDGF. For example, expression of NG2 enhances proliferation and migration of various cells in response to PDGF AA (Grako and Stallcup, 1995; Nishiyama et al., 1996b). Increased levels of NG2 and PDGF $\alpha \mathrm{R}$ observed on $j p$ progenitor cells may facilitate their response to limited amounts of PDGF AA. The chemokine GRO-1 has a synergistic effect on PDGF-driven OPC proliferation in the rat spinal cord (Robinson et al., 1998).

Chemokines are small, secreted proteins initially defined as chemoattractants for leukocytes that play an important role in inflammation (Rollins, 1997; Luster, 1998; Ransohoff and Tani, 1998). GRO-1 belongs to the $\alpha$ or CXC family of chemokines and functions as a chemoattractant for neutrophils. The mouse homolog KC was originally identified in $3 \mathrm{~T} 3$ fibroblasts stimulated by PDGF (Cochran et al., 1983; Oquendo et al., 1989), and its human homolog MGSA stimulates proliferation of melanoma cells (Richmond et al., 1988). The hamster GRO- $\alpha$ was initially identified as a molecule present in tumorigenic cells but not in nontumorigenic cells (Anisowicz et al., 1987). These findings indicate that members of the GRO-1 family of chemokines are involved in the regulation of growth control. $J p$ spinal cord contains elevated levels of GRO-1 mRNA and protein. GRO-1 in $j p$ spinal cord is primarily localized in astrocytes, and the increased expression in $j p$ spinal cord may reflect the activated state of these cells. Consistent with this hypothesis, the expression of other chemokines, such as monocyte chemoattractant protein-1, has been shown to be elevated in reactive astrocytes in experimental autoimmune encephalitis (Glabinski et al., 1997). In contrast to the greatly elevated levels of GRO-1 in jp spinal cord, the level of GRO-1 mRNA was not significantly elevated in jp cerebrum. This may be attributable to cortical gray matter present in the corpus callosum extracts. Alternatively, there may be inherent differences between corpus callosum and spinal cord white matter. This would be consistent with our observation that the number of proliferating OPCs is not as elevated in $j p$ corpus callosum as in jp spinal cord.

We propose that the elevated proliferation of OPCs in the jp spinal cord is a reflection of increased expression of the chemokine GRO-1. In this model, the extensive oligodendrocyte death in jp CNS caused by the point mutation in the PLP gene triggers a chain of events including activation of microglia (Sidman et al., 1964; Vela Hernandez et al., 1997) and subsequent reactive astrogliosis (Skoff, 1976; Vela et al., 1996). One consequence of the local activation of astrocytes is the increased secretion of GRO-1 that allows local proliferation of $\mathrm{NG} 2+\mathrm{OPCs}$ by synergistic 
action with low levels of PDGF. This is supported by our in vitro studies in which jp spinal cord extracts showed a growthstimulatory effect on OPCs and this effect could be inhibited by immunodepleting GRO-1 from the extracts. These studies demonstrate for the first time altered expression of chemokines in a naturally occurring noninflammatory lesion of the CNS and suggest that chemokines secreted by endogenous neural cells may exert their effects on endogenous CNS cells. This provides a novel mechanism by which the proliferation of OPCs is regulated in response to an insult in the postnatal CNS.

\section{REFERENCES}

Anisowicz A, Bardwell L, Sager R (1987) Constitutive overexpression of a growth-regulated gene in transformed Chinese hamster and human cells. Proc Natl Acad Sci USA 84:7188-7192.

Austyn JM, Gordon S (1981) F4/80, a monoclonal antibody directed specifically against the mouse macrophage. Eur J Immunol 11:805-815.

Beck KD, Powell-Braxton L, Widner H-R, Valverde J, Hefti F (1995) Igf1 gene disruption results in reduced brain size, CNS hypomyelination, and loss of hippocampal granule and striatal parvalbumincontaining neurons. Neuron 14:717-730.

Bell GI, Stempien MM, Fong NM, Rall LB (1986) Sequences of liver cDNAs encoding two different mouse insulin-like growth factor I precursors. Nucleic Acids Res 14:7873-7882.

Calver AR, Hall AC, Yu W-P, Walsh FS, Heath JK, Betsholtz C, Richardson WD (1998) Oligodendrocyte population dynamics and the role of PDGF in vivo. Neuron 20:869-882.

Carson MJ, Behringer RR, Brinster RL, McMorris FA (1993) Insulinlike growth factor I increases brain growth and central nervous system myelination in transgenic mice. Neuron 10:729-740.

Chirgwin JM, Przybyla AE, MacDonald RJ, Rutter WJ (1979) Isolation of biologically active ribonucleic acid from sources enriched in ribonuclease. Biochemistry 18:5294-5299.

Cochran BH, Reffel AC, Stiles CD (1983) Molecular cloning of gene sequences regulated by platelet-derived growth factor. Cell 33:939-947.

Glabinski AR, Tani M, Strieter RM, Tuohy VK, Ransohoff RM (1997) Synchronous synthesis of $\alpha$ - and $\beta$-chemokines by cells of diverse lineage in the central nervous system of mice with relapses of chronic experimental autoimmune encephalomyelitis. Am J Pathol 150:617-630.

Gow A, Southwood CM, Lazzarini RA (1998) Disrupted proteolipid protein trafficking results in oligodendrocyte apoptosis in an animal model of Pelizaeus-Merzbacher disease. J Cell Biol 140:925-934.

Grako K, Stallcup WB (1995) Participation of the NG2 proteoglycan in rat aortic smooth muscle cell responses to platelet-derived growth factor. Exp Cell Res 22:231-240.

Grinspan JB, Coulalaglou M, Beesley JS, Carpio DF, Scherer SS (1998) Maturation-dependent apoptotic cell death of oligodendrocytes in myelin-deficient rats. J Neurosci Res 54:623-634.

Hasel KW, Glass JR, Godbout M, Sutcliffe JG (1991) An endoplasmic reticulum-specific cyclophilin. Mol Cell Biol 11:3484-3491.

Hirano M, Goldman JE (1988) Gliogenesis in rat spinal cord: evidence for origin of astrocytes and oligodendrocytes from radial precursors. J Neurosci Res 21:155-167.

Ikenaka K, Furuichi T, Iwasaki Y, Moriguchi A, Okano H, Mikoshiba K (1988) Myelin proteolipid protein gene structure and its regulation of expression in normal and jimpy mutant mice. J Mol Biol 199:587-596.

Kligman D, Hilt DC (1988) The S100 protein family. Trends Biochem Sci 13:437-443.

Knapp PE, Skoff RP, Redsone DW (1986) Oligodendroglial cell death in jimpy mice: an explanation for the myelin deficit. $J$ Neurosci 6:2813-2822.

Kraus-Ruppert R, Herschkowitz N, Furst S (1973) Morphological studies on neuroglial cells in the corpus callosum of the jimpy mutant mouse. J Neuropathol Exp Neurol 32:197-203.

Levine JM, Nishiyama A (1996) The NG2 chondroitin sulfate proteoglycan: a multifunctional proteoglycan associated with immature cells. Perspect Dev Neurobiol 3:245-259.

Levine JM, Stincone F, Lee YS (1993) Development and differentiation of glial precursor cells in the rat cerebellum. Glia 7:307-321.

Luster AD (1998) Chemokines-chemotactic cytokines that mediate inflammation. N Eng J Med 338:436-445.

Marmur R, Kessler JA, Zhu G, Gokhan S, Mehler MF (1998) Differentiation of oligodendroglial progenitors derived from cortical multi- potent cells requires extrinsic signals including activation of gp130/ LIF $\beta$ receptors. J Neurosci 18:9800-9811.

Matthews MA, Duncan D (1971) A quantitative study of morphological changes accompanying the initiation and progress of myelin production in the dorsal funiculus of the rat spinal cord. J Comp Neurol 142:1-22.

McKinnon RD, Piras G, Ida Jr JA, Dubois-Dalcq M (1993) A role for TGF- $\beta$ in oligodendrocyte differentiation. J Cell Biol 121:1397-1407.

McKnight AJ, Macfarlane AJ, Dri P, Turley L, Willis AC, Gordon S (1996) Molecular cloning of F4/80, a murine macrophage-restricted cell surface glycoprotein with homology to the G-protein-linked transmembrane 7 hormone receptor family. J Biol Chem 271:486-489.

McMorris FA, Dubois-Dalcq M (1988) Insulin-like growth factor I promotes cell proliferation and oligodendroglial commitment in rat glial progenitor cells developing in vitro. J Neurosci Res 21:199-209.

McMorris FA, Smith TM, DeSalvo S, Furlanetto RW (1986) Insulin-like growth factor I/somatomedin C: a potent inducer of oligodendrocyte development. Proc Natl Acad Sci USA 83:822-826.

Meier C, Bischoff A (1975) Oligodendroglial cell development in jimpy mice and controls. J Neurol Sci 26:517-528.

Mercola M, Wang CY, Kelly J, Brownlee C, Jackson-Grusby L, Stiles C, Bowen-Pope D (1990) Selective expression of PDGF A and its receptor during early mouse embryogenesis. Dev Biol 138:114-122.

Miller DA, Lee A, Pelton RW, Chen EY, Moses HL, Derynck R (1989a) Murine transforming growth factor-beta 2 cDNA sequence and expression in adult tissues and embryos. Mol Endocrinol 3:1108-1114.

Miller DA, Lee A, Matsui Y, Chen EY, Moses HL, Derynck R (1989b) Complementary DNA cloning of the murine transforming growth factor-beta 3 (TGF beta 3 ) precursor and the comparative expression of TGF beta 3 and TGF beta 1 messenger RNA in murine embryos and adult tissues. Mol Endocrinol 3:1926-1934.

Nave KA, Lai C, Bloom FE, Milner RJ (1986) Jimpy mutant mouse: a 74-base deletion in the mRNA for myelin proteolipid protein and evidence for a primary defect in RNA splicing. Proc Natl Acad Sci USA 83:9264-9268.

Nave KA, Bloom FE, Milner RJ (1987) A single nucleotide difference in the gene for myelin proteolipid protein defines the jimpy mutation in mouse. J Neurochem 49:1873-1877.

Nishiyama A, Lin X-H, Giese N, Heldin C-H, Stallcup WB (1996a) Co-localization of $\mathrm{NG} 2$ proteoglycan and PDGF $\alpha$ receptor on $\mathrm{O} 2 \mathrm{~A}$ progenitor cells in the developing rat brain. J Neurosci Res 43:299-314.

Nishiyama A, Lin X-H, Giese N, Heldin C-H, Stallcup WB (1996b) Interaction between $\mathrm{NG} 2$ proteoglycan and PDGF $\alpha$ receptor on $\mathrm{O} 2 \mathrm{~A}$ progenitor cells is required for optimal response to PDGF. J Neurosci Res 43:315-330.

Nishiyama A, Yu M, Drazba JA, Tuohy VK (1997) Normal and reactive $\mathrm{NG} 2+$ glial cells are distinct from resting and activated microglia. J Neurosci Res 48:299-312.

Oquendo P, Alberta J, Wen D, Graycar JL, Derynck R, Stiles CD (1989) The platelet-derived growth factor-inducible $\mathrm{KC}$ gene encodes a secretory protein related to platelet $\alpha$-granule proteins. J Biol Chem 264:4133-4137.

Pringle NP, Richardson WD (1993) A singularity of PDGF alphareceptor expression in the dorsoventral axis of the neural tube may define the origin of the oligodendrocyte lineage. Development 117:525-533.

Pringle NP, Mudhar HS, Collarini EJ, Richardson WD (1992) PDGF receptors in the rat CNS: during late neurogenesis, PDGF alphareceptor expression appears to be restricted to glial cells of the oligodendrocyte lineage. Development 115:535-551.

Raff MC, Lillien LE, Richardson WD, Burne JF, Noble MD (1988) Platelet-derived growth factor from astrocytes drives the clock that times oligodendrocyte development in culture. Nature 333:562-565.

Ransohoff RM, Tani M (1998) Do chemokines mediate leukocyte recruitment in post-traumatic CNS inflammation? Trends Neurosci 21:154-159.

Richardson WD, Pringle N, Mosley MJ, Westermark B, Dubois-Dalcq M (1988) A role for platelet-derived growth factor in normal gliogenesis in the central nervous system. Cell 53:309-319.

Richmond A, Balentien E, Thomas HG, Flaggs G, Barton DE, Spiess J, Bordoni R, Francke U, Derynck R (1988) Molecular characterization and chromosomal mapping of melanoma growth stimulatory activity, a growth factor structurally related to $\beta$-thromboglobulin. EMBO J 7:2025-2033.

Robinson S, Miller R (1996) Environmental enhancement of growth 
factor-mediated oligodendrocyte precursor proliferation. Mol Cell Neurosci 8:38-52.

Robinson S, Tani M, Strieter RM, Ransohoff RM, Miller RH (1998) The chemokine growth-regulated oncogene- $\alpha$ promotes spinal cord oligodendrocyte precursor proliferation. J Neurosci 18:10457-10463.

Rollins BJ (1997) Chemokines. Blood 90:909-928.

Sasahara M, Fries JWU, Raines EW, Gown AM, Westrum LE, Frosch MP, Bonthron DT, Ross R, Collins T (1991) PDGF B-chain in neurons of the central nervous system, posterior pituitary, and in a transgenic model. Cell 64:217-227.

Sidman RL, Dickie MM, Appel SH (1964) Mutant mice (Quaking and Jimpy) with deficient myelination in the central nervous system. Science 144:309-311.

Skoff RP (1976) Myelin deficit in the Jimpy mouse may be due to cellular abnormalities in astroglia. Nature 264:560-562.

Skoff RP (1982) Increased proliferation of oligodendrocytes in the hypomyelinated mouse mutant-jimpy. Brain Res 248:19-31.

Skoff RP (1995) Programmed cell death in the dysmyelinating mutants. Brain Pathol 5:283-288.

Spassky N, Goujet-Zalc C, Parmantier E, Olivier C, Martinez S, Ivanova A, Ikenaka K, Macklin W, Cerruti I, Zalc B, Thomas JL (1998) Multiple restricted origin of oligodendrocytes. J Neurosci 18:8331-8343.

Sturrock RR (1980) Myelination of the mouse corpus callosum. Neuropathol Appl Neurobiol 6:415-420.

Tani M, Fuentes ME, Peterson JW, Trapp BD, Durham SK, Loy JK, Bravo R, Ransohoff RM, Lira SA (1996) Neutrophil infiltration, glial reaction, and neurological disease in transgenic mice expressing the chemokine N51/KC in oligodendrocytes. J Clin Invest 98:529-539.

Timsit S, Martinez S, Allinquant B, Peyron F, Puelles L, Zalc B (1995) Oligodendrocytes originate in a restricted zone of the embryonic ventral neural tube defined by DM-20 mRNA expression. J Neurosci 15:1012-1024.

Unsicker K, Flanders KC, Cissel DS, Lafyatis R, Sporn MB (1991) Transforming growth factor beta isoforms in the adult rat central and peripheral nervous system. Neuroscience 44:613-625.

Vela JM, Dalmau I, Gonzalez B, Castellano B (1996) The microglial reaction in spinal cords of jimpy mice is related to apoptotic oligodendrocytes. Brain Res 712:134-142.

Vela Hernandez JM, Dalmau I, Gonzalez B, Castellano B (1997) Abnormal expression of the proliferating cell nuclear antigen (PCNA) in the spinal cord of the hypomyelinated Jimpy mutant mice. Brain Res 747:130-139.

Vermeesch MK, Knapp PE, Skoff RP, Studzinski DM, Benjamins JA (1990) Death of individual oligodendrocytes in jimpy brain precedes expression of proteolipid protein. Dev Neurosci 12:303-315.

Warf BC, Fok-Seang J, Miller RH (1991) Evidence for the ventral origin of oligodendrocyte precursors in the rat spinal cord. J Neurosci 11:2477-2488.

Yeh HJ, Ruit KG, Wang YX, Parks WC, Snider WD, Deuel TF (1991) PDGF A-chain gene is expressed by mammalian neurons during development and in maturity. Cell 64:209-216. 